\title{
The Implementation Strategies of Individualized Education in the Field of Basic Education
}

\author{
Yaqin Zhang1 ${ }^{*}$, Yibei $\mathbf{L i}^{2}$ \\ ${ }^{1}$ Chengdu Normal University Teacher Education College, Chengdu, China \\ ${ }^{2}$ Paotongshu Primary School West District Campus, Chengdu, China \\ Email: *yujinn521@126.com
}

How to cite this paper: Zhang, Y.Q. and Li, Y.B. (2019) The Implementation Strategies of Individualized Education in the Field of Basic Education. Open Journal of Social Sciences, 7, 223-232. https://doi.org/10.4236/jss.2019.76018

Received: May 6, 2019

Accepted: June 24, 2019

Published: June 27, 2019

Copyright (๑) 2019 by author(s) and Scientific Research Publishing Inc. This work is licensed under the Creative Commons Attribution International License (CC BY 4.0).

http://creativecommons.org/licenses/by/4.0/

\begin{abstract}
Basic education, as a foundation project to cultivate intellectuals and upgrade the national quality, plays an important role in the education of all countries. In China, "creating education suitable for students" is the development direction of basic education. Following the direction, individualized education shows great respect for individual differences of students, thus sticking to the principle of "student-oriented". This paper extracts the implementation strategies of individualized education from the perspective of learning methods, curriculum implementation and operation, teaching methods and curriculum system construction.
\end{abstract}

\section{Keywords}

Basic Education, Individualized Education, Implementation Strategy

\section{Introduction}

Basic education, as a foundation project to cultivate intellectuals and upgrade the national quality, plays an important role in the education of all countries. "Currently, the development mode of the basic education in China is transforming from 'producing students suitable for education' to 'creating the education suitable for students', with the core value of 'student-oriented' education. The individualized education is the response to the educational fairness for all and the high-quality education of teaching students in accordance with their aptitude in practice" [1]. The individualized education can effectively promote students to get full development through their own different advantages, in order to exploit and develop the potentialities of each student, thus integrating the 
concept and educational teaching methods of "teaching students in accordance with their aptitude" into the professional development of educators.

We should realize that diversified ways are needed in students' learning, which is also affected by many factors including school culture, family culture, social environment and so on at the same time. Then, how does the individualized education respond to "different" individual learners with "rich" educational methods? To answer the question, "we need to think about what the concept of education development ought to be. What's more, we need to explore the workable practice category based on the concept of individualized education" [1], enriching the framework and operating system of individualized education.

\section{Research Methods-Action Research and Case Study}

The research unfolds the discussion taking the question as the core with, taking example by the Action Model of Kemmis. The educated, educators and educational effect are the basic elements of educational activities, with curriculum as the main carrier of educational effect. From the perspective of learning methods, curriculum implementation and operation, teaching methods and curriculum system construction, the research puts forward four individualized education propositions including "tailored teaching plans for individual student", "tailored teaching plans for each lesson", "family-like care from educators" and "education without boundaries", No questions, no action researches. Without action research, teaching will be inflexible and formalistic. According to Australian scholars Carr, W. and Kemmis, S., "The action research is a self-reflective inquiry conducted by practitioners in social contexts to improve their own practices, their understanding of these practices, and the background and origin of them" [2]. On the other hand, case study is an important part and the core content of individualized research. The research of individualized education will play a vital role in the physical and mental development of each student ultimately.

The research is conducive to the test of theories, plans, ideas and plans of individualized education in actual teaching process. It also involves various assumptions, theories, techniques and methods when solving problems. The contents mentioned above are not previous assumptions in the presupposition, but are constantly revised and perfected by in teaching practice by educators.

\section{Research Process and Analysis}

Based on the future development patterns of basic education and the development method of classroom culture improvement, the research has practiced the individualized education concepts including "tailored teaching plans for individual student", "tailored teaching plans for each lesson", "family-like care from educators" and "education without boundaries", in order to explore "how to provide suitable education for every child". The findings are as follows: 


\section{1) Learning Methods-Multiple Benefits of "Tailored Teaching Plans for} Individual Student"

Individualized education shall focus on the development of students. Firstly, it should face all the students; Secondly, it should center on the all-round development of each student; Thirdly, the principle of teaching students in accordance with their aptitude should be adhered to in consideration of personality development of each student. Therefore, the first key element of individualized education is to understand students. "Tailored teaching plans for individual student" does not only help educators understand students, but also assists students to identify and develop their interests and specialty through flexible teaching methods that give them a variety of options.

For example, a student is weak in abstraction and generalization because of the developmental retardation of abstract thinking caused by serious sensory integration dysfunction. Therefore, his (or her) logical reasoning in mathematics is deficient, and is unable to find the way to deduce the unknown from known conditions.

"Tailored teaching plans for individual student is to provide scientific design, future planning and professional guidance for individual learning processes, learning methods and growth visions from the view of lifelong development. It will design a full set of professional plans of individualized education programs for each student, with the allocation of the most appropriate teaching resources and individualized learning assistance programs, and the prescription of learning guidance processes" [1].

Therefore, the guidance for the student's mathematics learning should be implemented as follows. a) To establish a harmonious relationship between teachers and students. b) To optimize the class and stimulate the interest of mathematics learning. c) To cooperate with family members for joint supervision. d) To realize mutual assistance among classmates.

Meanwhile, the research of "tailored teaching plans for individual student" can benefit educators in many aspects, and arose thoughts as follows:

Firstly, educators should pay active attention to individual student, taking individual family background, personal interests and learning dilemma into consideration. "Tailored teaching plans for individual student" improves the attention of educators to individual differences of students. Besides, it promotes the research awareness of individualized education of educators.

Secondly, educators should take the initiative to solve the problem. Taking the question as the core, they ought to work out teaching strategies purposefully to make a breakthrough in existing learning situation. In the past, educators found and solved problems in the classroom passively. However, "tailored teaching plans for individual student" requires them to investigate students' background in advance, to design a set of effective teaching guidance programs through prudent thinking, and to compare and introspect in the observation.

Thirdly, educators' ability to introspect will be improved. "Introspection is the 
reflection on one's own thoughts and psychological feelings" [3]. It is a way of thinking. John Dewey, an American educator proposed in "How We Think, EXperience and Education" that "introspective thinking is the repeated, serious, continuous reflection on a problem" [4]. Teaching reflection is a kind of practical reflection. "It is a process in which educators review and analyze their own teaching behavior, decision-making and results, taking their own teaching process as the object" [5]. Some researchers have found that "educators constantly introspect their own teaching practice with the help of action research, actively exploring and solving the problems in educational practice. They will combine "Learning to learn" with "Learning to teach", striving to improve the rationality of teaching practice, in order to make themselves scholar-type educators" [6].

Fourthly, the enthusiasm for learning of educators can be aroused. Since the experience of cases in the "tailored teaching plans for individual student" is summed up by front-line educators in the classroom, it is of great practicability. The sharing of "tailored teaching plans for individual student" also promotes educators' professional learning and actively builds a learning community. Through the exchange, communication and sharing of the practicing of "tailored teaching plans for individual student", educators can learn from and sum up the experience, and jointly explore the methods and strategies of education and teaching reform. In a related study, a teacher interviewed said:

According to the requirements of individualized education, we put forward the observation tools of "tailored teaching plans for individual student": First, learning observation, including "student observation", "learning observation", "learning method observation", "knowledge point observation" and "class hour observation". Second, learning findings ... Third, learning diagnosis, to find corresponding tools for the strengths and shortcomings according to the findings above. Fourth, learning map. The path of each child s learning is different, which interlace together forming a map with personal style.

In the study of "tailored teaching plans for individual student", educators are not only educational practitioners, researchers, and reflectors, but also learners. Therefore, the research method of various achievements promotes the diversification of educators' identities. As a principal said:

Individualized education is the platform for us to learn and think. It reminds us of the understanding of education in the hectic routine work. The various achievements of a teaching plan make our educators play different roles, prompting us to accelerate the pace of progress, in order to better guide the development of children.

2) Curriculum Implementation and Operation-The Wisdom of "Tailored Teaching Plans for Each Lesson"

"Tailored teaching plans for each lesson is to reconstruct and implement classroom teaching in a way suitable for students' learning needs, including the choice of learning content, the use of teaching methods and the design of learn- 
ing strategies, in order to create a classroom suitable for each student based on the characteristics of personality development such as learning style, academic development level, and so on" [7]. Therefore, tailored teaching plans for each lesson contains rich wisdom of teaching.

For example, according to researches of different disciplines, the following problems can be found in current coursework. First, the contents are boring. Most of the homework is inflexible and monotonous exercises; Second, the tasks are unified. All students will submit consistent homework; Third, the evaluation is monotonous. Everything is decided by the teacher's say, without communication or cooperation.

To solve the above problems, the improvement methods are put forward-the principles of homework design are as follows. First, to be interesting. Stimulate students interest in learning and transfer it to homework. In order to eradicate the boredom homework, a lot of effective methods can be found starting from the needs of students. For example, the relayed diary is a good choice, through which students are able to show their opinions and aspirations.

Second, the contents should be diversified. For example, a weekly report can change to a relayed diary, transcription to knowledge combing tabloids, exercises to mistakes correcting, word transcription of weekly newspaper to self-made word cards.

Third, the way of presentation should be diversified. For example, reading aloud can change to performing, composition notebooks to composition anthologies.

Therefore, the four key elements of individualized education are embodying in the teaching wisdom of tailored teaching plans for each lesson:

First, the relationship between subject knowledge and curriculum should be understood. In the process of individualized education research, the attention is gradually paid to the independence, autonomy and difference of students, to understand subject knowledge and discover teaching problems from the teaching practice. "The curriculum is composed of subject knowledge and teaching methodology. The pedagogical content knowledge, which is the combination of subject knowledge and teaching methodology, is the most suitable for germane to its teachability among all the forms of subject knowledge" [8]. Whether the educators can transform the subject knowledge into forms meaningful to teaching, to adapt to different abilities and backgrounds of students "depends on teaching ability and method of educators of specific subjects and the ability and method to make students to master relevant concepts and processes. Therefore, before carrying out individualized education, teachers must understand not only the students, but also the subject knowledge and the relationship between the contents and the curriculum" [9].

Second, the "Large Space" thinking must be provided. Under the principle of "Discuss teaching through learning", the statement "Learning process is the process in which students actively construct the system of knowledge" has reached 
a consensus. Therefore, how can we promote the independent knowledge construction of students with different personality characteristics, different cognitive starting point, different experience basis, different ways of thinking and paths? The differences of students make the classroom "colorful but complex". The study found that the best way to deal with "differences" is to create the "Large Space" thinking, which is a real respect for the differences. "Large Space" is the gap between a student's possible developmental level (i.e. the potential achieved through teaching) and the student's current level (i.e. the level achieved when solving problems in independent learning). In the "Large Space" thinking, the curriculum must be designed according to the problem, which requires careful preparation. The attention should be given to worthwhile issues with sufficient time and focus.

Third, the intelligent library of teaching strategies should be put into use. It is very important for teachers to experience teaching wisdom and tactics in the implementation of "Large Space" class. "Teaching strategy is the pith of the teaching wisdom and art of an educator, and the presentation of their professionalization. Different teachers use different strategies. Even the same strategy used by different teachers will show different styles. Teaching strategy and its use is full of educators' personalities" [10].

Fourth, individualized evaluation and homework design shall be taken seriously. Many study groups were formed in the course of the study. The combination of students with different personalities can also cultivate students' abilities that need to be improved. By analyzing many evaluations among group members, including self-evaluation, mutual evaluation or intra-group evaluation, it is found that students possess unique vision and views. Besides, these evaluations also show that "the respect for students right to speak" plays a positive role in greatly increasing students' participation and improving their learning quality in an all-round way. Professor David Hargreaves of Cambridge University believes that "the respect for students right to speak" is one of the ways of individualized education. The student evaluation in the aspect of individualized education, with the method of "the respect for students right to speak", "can help students build self-confidence and self-esteem, forming the traits needed for being responsible and creative citizens, including tolerance, friendliness, respect for authority and courage to challenge authority, and the ability of public speaking" [11].

3) Teaching Methods-The Personalities of Educators Providing Family-like Care

Educators play the leading role in education. Individualized education requires teachers to change for the sake of students. "Family-like care from educators is to provide suitable development mode of profession. Starting from the internal needs, it adapts to, guides and meets diversified development requirements of profession of different educators, so as to help them grow into a professional leader through the development mode suitable for their own needs." 
[12] Educators grow up with the development of individualized education, gradually forming the individualized teaching of family-like care from educators. The study found that the understanding and the implementation of individualized education of educators are conducive to forming their individualized teaching style and comprehension.

The implementation of individualized education has certain requirements for the quality of educators-they can not only use proper teaching strategies, but also have a good emotional capacity. The educators' individualized teaching style is the unique educational values, ways of thinking, and educational behavior gradually formed in the long process of teaching practice. It is the embodiment of educators' personal temperament and personality. "Basically, it has three types: the characteristic of rational educators is to control teaching and the learning of students with individual reason. They can calmly handle the relationship between teaching and learning. Besides, they are good at thinking" [13]. Emotional educators dominate their teaching with emotion in teaching. They are often affected by emotions in their work, and their body movements are animated. They are especially good at verbal expression. The statement "I feel ..." often appears in their discourse. The most special characteristic of volitional teachers is the perseverance and fortitude when encountering the problems in teaching. They will keep going until achieving their goals. The teaching is controlled by the strong will. Of course, not all the educators are in the same type of teaching style in the research. In addition, the sharing of educators' practice will also promote the adjustment of their teaching style.

4) Construction of Curriculum System-International Curriculum without

\section{Boundaries}

The important symbol of modern education is the internationalization of education, aiming to cultivate students with an international perspective and to enhance students' international communication ability with an open attitude. "Classroom without boundaries is the definition of learning time and space in individualized education, that is, learning breaks through the limitations of the curriculum, teachers, classrooms and school life" [12]. While most of the activities of international curriculum are brain-based and hands-on education practice, in which students learn by communicating, discussing, visiting, interviewing, observing, investigating, producing, evaluating and performing with students from other schools. These ways of learning, which are beyond the scope provided by the regular classroom, are diversified, colorful, and vivid. This study found that extracurricular activities in international curriculum construction have educational value, the fundamental reason of which is that it has different characteristics from common conventional classroom teaching. First of all, it can create a real, vivid and lively learning environment for students. What's more, students can choose activities or extracurricular themes voluntarily according to their own interests, hobbies and abilities, and the learning content is not limited in the traditional syllabus. "The extracurricular activities of international curri- 
culum are an extension and complement to the classroom teaching. Therefore, it is the teaching system of extracurricular activities, independent of formal classroom teaching. It should have its own teaching plan, syllabus, and optional or self-compiled textbooks" [14].

Therefore, the extracurricular activities of international curriculum refer to the educational activities associated with formal curriculum, which play an auxiliary role. The activity design and classroom teaching of the international curriculum should supplement and promote each other. At the same time, the activities should be made into a series or a curriculum with precise institution. With the development of the society, international curriculum has become the carrier of the important extracurricular activities in the school. In addition, people also begin to realize that the extracurricular activities of international curriculum are valuable in many aspects. For example, it can stimulate students' interest in learning, broaden their horizons, increase and contact their knowledge, enrich their spiritual life, and promote their intellectual development. At the same time, it also combines teaching theory with learning practice, so that students get comprehensive and personal development.

\section{Suggestions and Measures}

The research makes a conclusion about the important elements of individualized education in the process of operation and implementation. In addition to focusing on the development of individual cognitive ability according to the nativism to understand students, it implements individualized teaching around the constructivist learning theory, and provides individualized interactive assessment, cooperative learning and borderless classroom activities from a social perspective of interpersonal interaction. Educators use their own practice to create the development of education and teaching, and promote the improvement of their professional quality as well. They have the courage to innovate teaching reform, making the classroom change. However, facing complex and changing educational environment, individual educators need to keep studying hard and innovating because teaching is not a personal matter, but is influenced by social culture, school culture, and teacher culture. The followings are two suggestions:

1) Strengthen Internal and External Cooperation: Effective and Close Cooperation with Educational Researchers

Educational research is to better promote the all-round development of students and to improve the quality of education and teaching. Only when a good professional development environment is equipped by educators can students get developed. The key of research lies in whether the research promotes the improvement of teaching and learning level. In order to realize the effectiveness of research, it is necessary to seek appropriate cooperation. Individualized education needs different types of experts into the school for guidance and help. And the support needed in specific stage should be clarified according to the current situation of teaching, educators and their needs. The clearer and the 
more accurate the needs are, the more appropriate the selection of experts will be, and more effective the guidance will be.

2) Pay Attention to Teacher Culture: Give Full Play to the Strength of Backbone Teachers in Teaching and Research

The teaching reform of individualized education is not only the change of behavior, but also the change of educators' beliefs. When practicing, they often focus on how to do, even if it is the same behavior. But different beliefs will lead to different training results. Belief dominates people's behavior and ability, and at the same time, it promotes the change of educators' self-identity role. Although the teaching knowledge of educators is a kind of practical knowledge, it cannot be separated from the influence of social culture and community interaction. "Therefore, it is not only a representation of personal knowledge, but also a symbol of the common knowledge of the community. The belief and value behind the practice control the teaching behavior. The value of knowledge lies in that it is implicit, which prompts educators to reflect and show implicit knowledge to make educators more aware of the importance of educational belief [15]. Therefore, the construction of backbone teachers' research team plays an important role in the improvement of teaching situation and leading the development of teachers. How to better play its role is what we have been paying attention to. In practice, we have adopted the "learning by doing" approach, so that backbone teachers and other teachers can conduct mutual learning and influence in the whole process of the decomposition of research tasks and the implementation of research plans. It needs to be more in-depth thinking, and to explore some conceptual issues, for example, "Why do this?" "What are the shortcomings of previous teaching?". Only when educators themselves are aware of the shortcomings of traditional teaching, can they calmly think about the concept of a good lesson, and then look for or learn new methods. If educators are in the culture where educators' learning is lacked in individualized education, it will be difficult to promote individualized education and educators' professional development to promote, and to seek change will be in a dilemma.

\section{Conflicts of Interest}

The authors declare no conflicts of interest regarding the publication of this paper.

\section{References}

[1] Wang, Z. (2012) Education Suits Students: Practice Category of Individualized Education. Journal of the Chinese Society of Education, No. 5, 13.

[2] Carr, W. and Kemmis, S. (1986) Becoming Critical: Education, Knowledge and Action Research. Falmer Press, London, 164-165.

[3] Liu, L. and Liu, C. (2011) Two Forms of Reflection to Promote Teachers' Professional Development. Journal of Tianjin Institute of Education and Science, No. 5, 54.

[4] Dewey, J. (2005) How We Think, Experience and Education. 2nd Edition, People's 
Education Press, Beijing, 23.

[5] Zhang, J. (1997) Reflection: A New Way to Improve Teachers' Teaching Behavior. Journal of BNU (Social Sciences Edition), No. 4, 56.

[6] Wang, K. and Yang, Y. (2010) On Reflective Teaching and Development of College English Professors. Journal of Jilin Normal University of Engineering Technology, No. 5, 46-47.

[7] Wang, Z. (2012) Education Suits Students: Practice Category of Individualized Education. Journal of the Chinese Society of Education, No. 5, 14.

[8] Zhu, X. and Tao, B. (2006) Two Approaches to the Study of Pedagogical Knowledge on Disciplines in Western. Elementary \& Secondary Schooling Abroad, No. 3, 32.

[9] Shulman, L.S. (1986) Those Who Understand: Knowledge Growth in Teaching. Educational Researcher, 15, 4.

[10] Tian, L. and Liu, D. (2003) Teaching Strategies: A Medium Bridge between Teaching Ideas and Teaching Actions. Educational Research and Experiment, No. 5, 61.

[11] Zhao, Y. (2012) Employment? Starting a Business? Educational Science Publishing House, Beijing, 179.

[12] Wang, Z. (2012) Education Suits Students: Practice Category of Individualized Education. Journal of the Chinese Society of Education, No. 5, 17.

[13] Chen, J. (2002) A Probe into the Individualization of Classroom Teaching. Education Exploration, No. 4, 74-75.

[14] Jiang, X. (2010) Individualized Teaching Strategy. Beijing Publishing Group, Beijing, 23.

[15] Liu, A. (2003) Tacit Knowledge: A New Perspective of Teachers' Professional Knowledge Base. Journal of Luoyang Normal University, No. 3, 105. 